Mini Review

\title{
Two-dimensional Material as Anode for Lithium Ion Batteries: Recent Progress
}

\author{
Guang Huang ${ }^{1 *}$, Bin Cai ${ }^{2 *}$, Changfa Zhan ${ }^{1}$ and Peng Sun ${ }^{1}$ \\ ${ }^{1}$ School of Conservation, Shanghai Institute of Visual Art, Songjiang 201620, Shanghai, P. R. China \\ ${ }^{2}$ School of Chemistry and Chemical Engineering, Zhoukou Normal University, Zhoukou 466001, P. \\ R. China \\ *E-mail: Guang Huang: guanghuang@aliyun.com Bin Cai: caib@actinide.org
}

doi: $10.20964 / 2020.06 .72$

Received: 21 January 2020 / Accepted: 23 March 2020 / Published: 10 May 2020

Compared with traditional bulk materials, two-dimensional nanomaterials exhibit peculiar physical and chemical properties. At present, two-dimensional nanomaterials have great application potential in the fields of medicine, aviation, energy and electronic information. To address both the energy and power demands of secondary LIBs for future energy storage applications, the development of innovative kinds of electrodes is required. In this review, we summarize the current development progress of twodimensional materials used as anodes in lithium-ion batteries. Specifically, graphene, two-dimensional phosphorene, $\mathrm{MoS}_{2}$ and MXene are highlighted.

Keywords: Two-dimensional material; MXene; Lithium ion batteries; $\mathrm{MoS}_{2}$; Two-dimensional phosphorene; Graphene

\section{$\underline{\text { FULL TEXT }}$}

(C) 2020 The Authors. Published by ESG (www.electrochemsci.org). This article is an open access article distributed under the terms and conditions of the Creative Commons Attribution license (http://creativecommons.org/licenses/by/4.0/). 